\title{
Carbon isotope variability in monosaccharides and lipids of aquatic algae and terrestrial plants
}

\author{
Bart E. van Dongen*, Stefan Schouten, Jaap S. Sinninghe Damsté \\ Department of Marine Biogeochemistry and Toxicology, Royal Netherlands Institute for Sea Research (NIOZ), PO Box 59, \\ 1790 AB Den Burg, Texel, The Netherlands
}

\begin{abstract}
The stable carbon-isotope compositions of individual monosaccharides and lipids, as well as the bulk stable carbon-isotope composition of total cell material from different aquatic and terrestrial plants were determined. With the exception of a Phaeocystis sp. bloom sample, monosaccharides were generally enriched in ${ }^{13} \mathrm{C}$ by 0 to $9 \%$ compared to the total cell material and significantly enriched (1 to $16 \%$ ) in ${ }^{13} \mathrm{C}$ compared to lipids (fatty acids, phytol, sterols and alkenones) within single organisms. The depletion of ${ }^{13} \mathrm{C}$ in $n$-alkyl lipids relative to monosaccharides was larger than the depletion of ${ }^{13} \mathrm{C}$ in isoprenoid lipids relative to monosaccharides. In addition, an isotopic enrichment was observed in the ${ }^{13} \mathrm{C}$ content of $\mathrm{C}_{5}$ monosaccharides compared to glucose in some of the organisms studied, indicating isotopic heterogeneity within carbohydrates. The magnitude of the differences between monosaccharides, total cell material and lipids was far greater than previously reported. Thus, selective assimilation of ingested carbohydrates can lead to isotopic enrichments of heterotrophic biomass and zooplankton and subsequent trophic levels. In addition, since dissolved organic carbon (DOC) and particulate organic carbon (POC) has a significant carbohydrate fraction, the $\delta^{13} \mathrm{C}_{\mathrm{POC}}$ and $\delta^{13} \mathrm{C}_{\mathrm{DOC}}$ signal will be significantly influenced by the relative amounts and the $\delta^{13} \mathrm{C}$ values of the carbohydrates present. This has significant implications for the isotopic integrity of the organic matter fractions during carbon cycling in food chains of aquatic ecosystems.
\end{abstract}

KEY WORDS: Carbohydrates $\cdot{ }^{13} \mathrm{C} \cdot$ Stable carbon isotope $\cdot$ Food web $\cdot$ Lipids $\cdot$ Aquatic $\cdot$ Terrestrial

\section{INTRODUCTION}

Carbohydrates are the most abundant biochemicals on earth (Aspinall 1983). For instance, carbohydrates comprise about $75 \mathrm{wt} \%$ of vascular plant tissues (Sjöström 1981) and 20 to $40 \mathrm{wt} \%$ of plankton (Parsons et al. 1984). The carbohydrates comprise the bulk of the biomass in marine and terrestrial environments together with proteins and lignins (Tissot \& Welte 1978, Parsons et al. 1984). In addition, carbohydrates are a significant component of oceanic dissolved organic matter (DOM; Mopper et al. 1980, Benner et al. 1992, Pakulski \& Benner 1994, McCarthy et al. 1996, Borch \& Kichman 1997, Skoog \& Benner 1997, Burdige et al. 2000). DOM represents one of the largest

*E-mail: dongen@nioz.nl dynamic reservoirs of reduced carbon on earth $\left(\sim 10^{18} \mathrm{~g}\right.$ carbon, i.e. the same magnitude as all living vegetation on the earth's continents), and is larger than the atmospheric $\mathrm{CO}_{2}$ pool (Hedges 1992). Because carbohydrates, together with proteins and lignins, represent $>40 \%$ of the degraded carbon, they are important nutrients for the benthic and pelagic communities (Cowie et al. 1992). Even at low concentrations, excreted carbohydrates provide a substantial food source for heterotrophic bacteria and zooplankton (Wright \& Hobbie 1966, Gocke 1975, Williams \& Yentsch 1976), as indicated by their rapid turnover rates.

In the assessment of food web structures in freshwater and marine ecosystems, the potential of stable carbon-isotope $\left(\delta^{13} \mathrm{C}\right)$ ratios as natural tracers in food chains is increasingly acknowledged (e.g. Michener \& Schell 1994) and a number of studies utilizing stable 
carbon isotopes have been published (e.g. Yoshii et al. 1999, Van der Zanden et al. 2000). These studies show that the $\delta^{13} \mathrm{C}$ of the heterotrophic biomass is primary influenced by the $\delta^{13} \mathrm{C}$ of the autotrophic food source. Consequently, because carbohydrates are an important constituent of autotrophic carbon and selective assimilation can take place (e.g. Volkman et al. 1980, Grice et al. 1998), the carbon-isotope composition of carbohydrates will significantly influence the carbonisotope composition of the heterotrophs and zooplankton. Thus, information on the carbon-isotope composition of carbohydrates is of primary importance for reconstructing food web relations based on isotopic compositions. In addition, since carbohydrates are an important component of DOM their carbon-isotope composition will significantly influence the bulk DOM carbon-isotope composition.

Until now, using bulk measurements, carbohydrates were generally thought to be slightly enriched in ${ }^{13} \mathrm{C}$. The magnitude of this enrichment was found to be up to 3 to $4 \%$ relative to total cell material and 4 to $10 \%$ relative to lipids (e.g. Deines 1980). Wong et al. (1975) reported an enrichment in ${ }^{13} \mathrm{C}$ of bacterial carbohydrates of up to $6 \%$ relative to the total cell material and up to $16 \%$ in ${ }^{13} \mathrm{C}$ relative to the lipids.

Very little is known about the $\delta^{13} \mathrm{C}$ values of carbohydrates at the molecular level. In contrast, much attention has been paid to another class of biochemicals, the lipids. This is mainly because of the easy accessibility of these compounds by gas chromatography techniques due to their apolar nature. Differences between $\delta^{13} \mathrm{C}$ values of individual lipids within single organisms were found to be large (Schouten et al. 1998). However, the magnitude of the biosynthetic enrichment of $\delta^{13} \mathrm{C}$ in monosaccharides relative to total cell material and lipids is unclear and detailed molecular isotopic analyses of individual monosaccharides are lacking. Recently, we developed a new method (Van Dongen et al. 2001) to reliably measure the $\delta^{13} \mathrm{C}$ values of individual monosaccharides. In this study we determined the stable carbon-isotope composition of individual monosaccharides in a range of marine and freshwater algae and terrestrial higher plants. These were compared with the ${ }^{13} \mathrm{C}$ content of the total cell material and individual lipids to infer the implications for carbon isotopic studies of food webs and carbon cycling in aquatic systems.

\section{MATERIALS AND METHODS}

Cell material. The aquatic and terrestrial plants that were analyzed in this study and their culture conditions or sampling sites are listed in Table 1. The freshwater species Tetraedron minimum, Scenedesmus communis and Pediastrum boryanum were cultured under conditions described by Blokker et al. (1998a,b). Two different cultures of T. minimum were cultured, 1 continuous culture and 1 batch culture. The continuous culture was kept at a constant $\mathrm{pH}$ of 7.0 , while the $\mathrm{pH}$ of the batch culture was between 5 and 6 at the start and between 8 and 9 at the end. Cultures of the marine species Isochrysis galbana and Rhodomonas sp. were grown in Erlenmeyer flasks (3 l) with a continuous air supply. Light was kept on a 16:8h light: dark regime and dilution rates ranged between 0.13 and $0.22 \mathrm{~d}^{-1}$. The algae were grown on $F / 2$ medium (Guillard 1975). The alga Phaeocystis sp. was collected with plankton nets (50 $\mu \mathrm{m}$ mesh) during spring blooms in the western Dutch Wadden Sea and the southern North Sea in 1991 and 1992 and stored frozen $\left(-20^{\circ} \mathrm{C}\right)$ until use. Field specimens of Sphagnum cuspidatum and the roots of Erica tetralix were obtained from the peat bog reserve 'Bargerveen' (Zwartemeer, SE Drenthe, The Netherlands: Baas et al. 2000). Immediately after collection, the plants were washed repeatedly with water and any non-indigenous material was removed. The samples were stored frozen until use.

Table 1. Aquatic and terrestrial plants analyzed in this study with their culture or field condition

\begin{tabular}{|c|c|c|c|c|c|}
\hline Organism & Class & Culture type & Sampling site & $\mathrm{T}\left({ }^{\circ} \mathrm{C}\right)$ & $\mathrm{CO}_{2}$ source \\
\hline \multicolumn{6}{|l|}{ Freshwater } \\
\hline Tetraedron minimum & Chlorophyceae & Batch/Continuous & - & 19 & $\mathrm{Air}+2 \% \mathrm{CO}_{2}$ \\
\hline Scenedesmus communis & Chlorophyceae & Batch & - & 19 & $\mathrm{Air}+2 \% \mathrm{CO}_{2}$ \\
\hline Pediastrum boryanum & Chlorophyceae & Batch & - & 19 & $\mathrm{Air}+2 \% \mathrm{CO}_{2}$ \\
\hline \multicolumn{6}{|l|}{ Marine } \\
\hline Isochrysis galbana & Haptophyceae & Continuous & - & 15 & Air \\
\hline Rhodomonas sp. & Cryptophyceae & Continuous & - & 15 & Air \\
\hline Phaeocystis sp. & Haptophyceae & - & North Sea bloom & - & Air \\
\hline \multicolumn{6}{|l|}{ Terrestrial } \\
\hline Sphagnum cuspidatum & Bryophyta & - & Bargerveen peat bog & - & Air \\
\hline Erica tetralix & Ericaceae & - & Bargerveen peat bog & - & Air \\
\hline
\end{tabular}




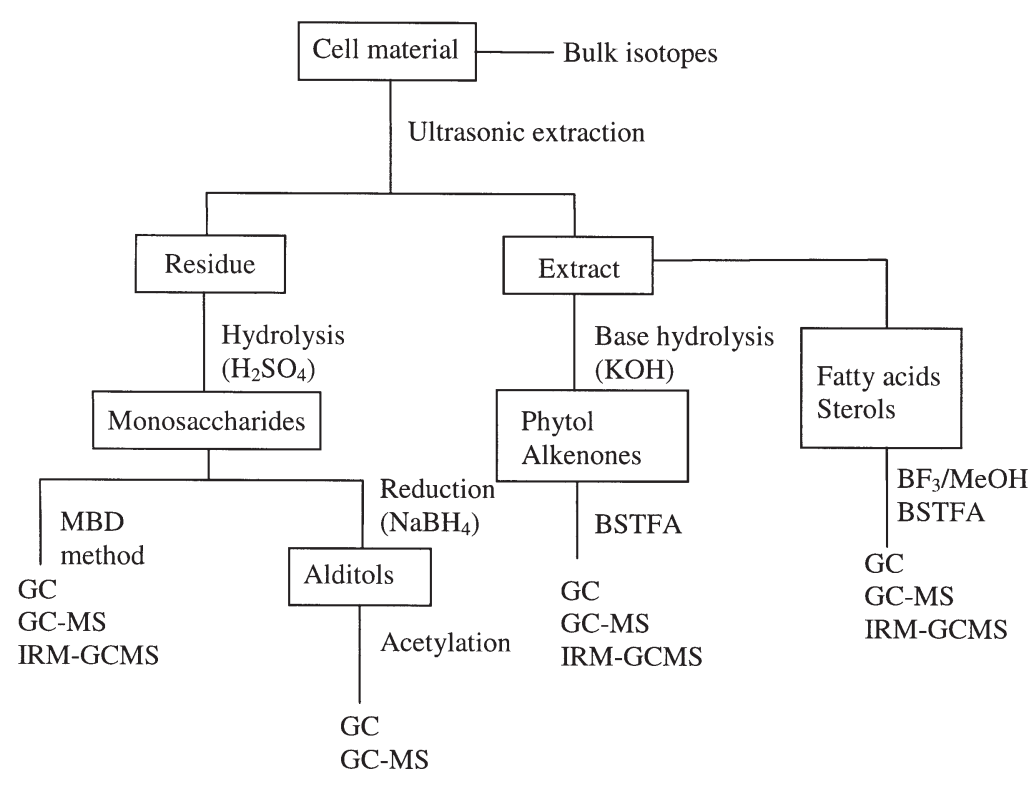

Fig. 1. Extraction and isolation scheme of plant cell material

rides are measured as their alditol acetates, the origin of some of the alditol acetates is uncertain. For instance, glucitol could originate from glucose as well as fructose (Macko et al. 1998). In these cases the results of the MBD method, which preserves the original isomeric structure, in combination with the alditol acetate method, were used to infer the origin of the different alditol acetates. The MBD method, a derivatization method to make monosaccharides GC-amenable, was used to determine the $\delta^{13} \mathrm{C}$ values of the different monosaccharides as described by Van Dongen et al. (2001). Typically, $0.5 \mathrm{ml}$ of a solution of $10 \mathrm{mg}$ methylboronic acid in $1 \mathrm{~mL}$ pyridine was added to the hydrolyzed material and the solution was heated at $60^{\circ} \mathrm{C}$ for $30 \mathrm{~min}$. Subsequently, $15 \mu l$ N,O-bis(trimethylsilyl)trifluoroacetamide (BSTFA) was added and the solution was stirred at

Monosaccharide analysis. Cell material of the plants was collected, freeze-dried and extracted as described by Schouten et al. (1998). The extraction, separation and identification of the monosaccharides as well as the lipids are schematically depicted in Fig. 1. Briefly, cell material was ultrasonically extracted with methanol $(3 \times)$, methanol/dichloromethane $(1: 1,3 \times)$ and hexane/dichloromethane (hex/DCM, 1:1, v/v mixture; $3 \times$ ). The extracts were analyzed for lipids as described in the following subsection. Approximately 7 to $15 \mathrm{mg}$ of dried residues left after extraction were stirred with $4 \mathrm{ml} 12 \mathrm{M} \mathrm{H}_{2} \mathrm{SO}_{4}$ at room temperature for $2 \mathrm{~h}$. The solution was diluted to $1 \mathrm{M}$ and the polysaccharides were hydrolyzed for $4.5 \mathrm{~h}$ at $85^{\circ} \mathrm{C}$. The acidic solution was neutralized with $\mathrm{BaCO}_{3}$. The precipitate was removed by centrifugation, the residue washed twice with bidistilled water and the combined water layers were freeze-dried. The hydrolyzed material was analyzed for monosaccharides using 2 different methods. To determine the relative amounts of the different monosaccharides, they were analyzed using the alditol acetate method as described by Klok et al. (1982, 1984). The methylboronic derivatization method (MBD method; described in subsection 'Instrumental analyses') was not used to determine the relative amounts of all the monosaccharides since the derivatization of a number of the monosaccharides is incomplete (Van Dongen et al. 2001). The alditol acetate method involves the reduction of monosaccharides with $\mathrm{NaBH}_{4}$ to alditols and acetylation of the alcohol groups using acetic anhydride and pyridine with the use of myoinositol as internal standard. Because the monosaccha- $60^{\circ} \mathrm{C}$ for $5 \mathrm{~min}$. To remove any solid material, the solution was filtered through a pipette filled with $\mathrm{MgSO}_{4}$ with ethyl acetate as an eluent. The solution was concentrated using evaporation under nitrogen as necessary. The monosaccharide fractions were analyzed by gas chromatography (GC), gas chromatography-mass spectro-metry (GC/MS), and isotope-ratio monitoring GC/MS (IRM-GC/MS) as described in 'Instumental analysis'.

Lipids. The separation and identification of lipids are schematically depicted in Fig. 1. Saponification, methylation and silylation were performed as described by Schouten et al. (1998). In some instances, phytol and sterols were present in relatively low amounts compared to fatty acids, and $\delta^{13} \mathrm{C}$ values could not be determined accurately. In these cases, the total ex-tracts were filtered over an $\mathrm{Al}_{2} \mathrm{O}_{3}$-column using ethyl acetate as an eluent to remove the fatty acids. The total extracts of Erica Tetralix and Sphagnum cuspidatum were eluted over a $\mathrm{SiO}_{2}-$ column using hex/DCM (9:1, v/v mixture) as eluent to collect the $n$-alkanes and DCM/methanol (1:1, v/v mixture) to collect the fatty acids and sterols and phytol. The long-chain alkenones present in Isochrysis galbana were measured in the saponified fraction to avoid co-elution with the long-chain alkenoates present. The lipid fractions were analyzed by GC, GC/MS and IRM-GC/MS as described in the following section.

Instrumental analyses. Gas chromatography (GC) was performed with a Hewlett Packard 6890 instrument and gas chromatography-mass spectrometry (GC-MS) using a Hewlett-Packard 5890 gas chromatograph interfaced with a VG Autospec Ultima mass 
spectrometer. Lipid analysis was carried out as described by Schouten et al. (1998). For analysis of alditol acetates, a fused silica capillary column $(1=25 \mathrm{~m}$; i.d. = $0.32 \mathrm{~mm}$ ) coated with CP Sil-88 (film thickness $0.25 \mu \mathrm{m})$ was used. Samples were dissolved in ethyl acetate and injected at $70^{\circ} \mathrm{C}$. The temperature was raised to $150^{\circ} \mathrm{C}$ at $20^{\circ} \mathrm{C} \mathrm{min}^{-1}, 3^{\circ} \mathrm{C} \mathrm{min}{ }^{-1}$ to $240^{\circ} \mathrm{C}$ and held for $10 \mathrm{~min}$. Since the number of added carbon atoms during the derivatization reaction is different for the different monosaccharides the relative amounts were corrected for added carbon. In order to measure The $\delta^{13}$ values of the monosaccharides, the MBD method was used for the derivatization as described by Van Dongen et al. (2001). The derivatized compounds were separated on a fused silica capillary column ( $1=$ $30 \mathrm{~m}$; i.d. $=0.32 \mathrm{~mm}$ ) coated with CP Sil-19 (film thickness $0.12 \mu \mathrm{m})$. Samples were injected at $70^{\circ} \mathrm{C}$ and the temperature was raised to $80^{\circ} \mathrm{C}\left(20^{\circ} \mathrm{C} \mathrm{min}{ }^{-1}\right)$ and held for $10 \mathrm{~min}$. Subsequently, the $\mathrm{GC}$ was heated at $4^{\circ} \mathrm{C}$ $\mathrm{min}^{-1}$ to $180^{\circ} \mathrm{C}$ followed by $10^{\circ} \mathrm{C} \mathrm{min}^{-1}$ to $280^{\circ} \mathrm{C}$ and held for $1 \mathrm{~min}$.

The alditol acetates and methyl boronic acid derivatives were identified on the basis of known relative retention times established by the analysis of standard mixtures and on the basis of mass spectra (Reinhold et al. 1974, Klok et al. 1982, 1984, Van Dongen et al. 2001).

Isotope-ratio-monitoring gas chromatography-mass spectrometry (IRM-GC-MS) was performed using a Finnigan DELTA-C. The same columns, column conditions and temperature program was used as in the case of GC analysis. The $\delta^{13} \mathrm{C}$ values reported were obtained by at least 2 analyses and the results were averaged to obtain a mean value. The MBD method implies the introduction of extra carbon atoms from the derivatization agent: 2 in the case of arabinose and xylose
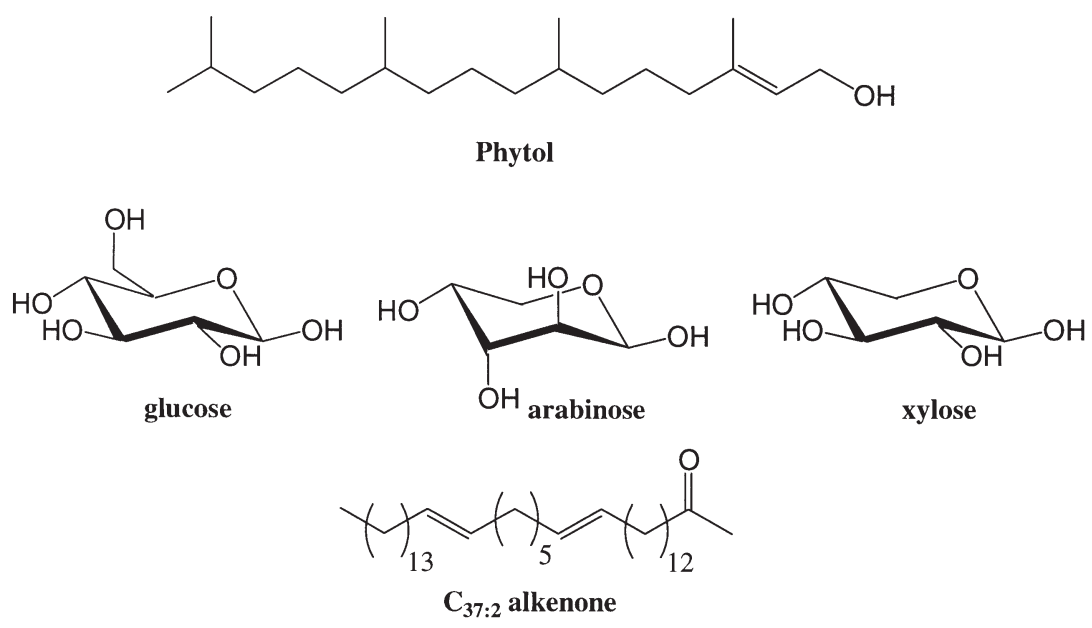

Fig. 2. Structures of the compounds analyzed and 5 in the case of glucose (Fig 2). To correct for the alteration in the stable carbon-isotope composition due to the introduction of these additional carbon atoms, the $\delta^{13} \mathrm{C}$ of the derivatization agents (methylboronic acid and BSTFA) were determined (Van Dongen et al. 2001). The corrections for the introduced carbon due to the methylation or silylation of the fatty acids, phytol and sterols were performed as described by Schouten et al. (1998). The stable carbon-isotope compositions are reported in delta notation as determined against the Vienna PDB ${ }^{13} \mathrm{C}$ standard.

The stable carbon-isotope composition of the bulk cell material $\left(\delta^{13} C_{\text {bulk }}\right)$ was determined by automatic online combustion (Carlo Erba CN analyser 1502 series) followed by conventional isotope ratio-mass spectrometry (Fisons optima: Fry et al. 1992).

\section{RESULTS AND DISCUSSION}

\section{${ }^{13} \mathrm{C}$ content of monosaccharides}

The monosaccharide fraction of the freshwater algae and the marine alga Rhodomonas sp. mainly consisted of glucose (65 to $90 \%$ ) and other $\mathrm{C}_{6}$-monosaccharides (mannose, rhamnose and galactose: Fig. 3). In Isochrysis galbana the major component was also glucose $(30 \%)$, but it was relatively less abundant. Phaeocystis sp. had as major monosaccharide arabinose (46\%), and the terrestrial plants Sphagnum cuspidatum and Erica tetralix xylose (24 and $47 \%$ ). In addition to these monosaccharides, considerable amounts of other $\mathrm{C}_{5}$ (mainly ribose), $\mathrm{C}_{6}$ (rhamnose, mannose and galactose) and $\mathrm{C}_{7}$-monosaccharides were found.

Using the MBD method, the $\delta^{13} \mathrm{C}$ values of the different monosaccharides (where possible) were determined (Table 2). For the cultured algae (except Isochrysis galbana) only the $\delta^{13} \mathrm{C}$ of glucose could be reliably determined. The contribution of other monosaccharides was too small and consequently could not been determined or, in the case of mannose, the derivatization by the MBD method was incomplete (Van Dongen et al. 2001) and the $\delta^{13} \mathrm{C}$ values obtained were deemed not reliable. For Isochrysis galbana, Phaeocystis sp. and both terrestrial plants, the $\delta^{13} \mathrm{C}$ of glucose and the $\mathrm{C}_{5}$-monosaccharides arabinose and/or xylose could be determined (Table 2). Sometimes small amounts $(<6 \%)$ of other monosaccharides were co-eluting with the $\mathrm{C}_{5}$ monosaccharides, i.e. fucose co-eluted 


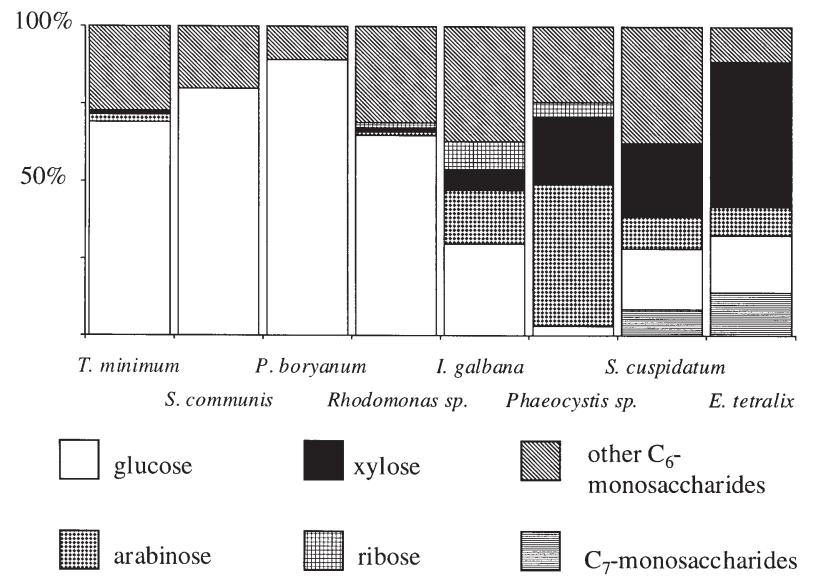

Fig. 3. Percentage of monosaccharides relative to total amount of alditols in different aquatic and terrestrial organisms. Other $\mathrm{C}_{6}$-monosaccharides included rhamnose, mannose, galactose and fucose. The structures of the $\mathrm{C}_{7}$-monosaccharides are unknown. Full specific names as in Table 1

with arabinose and ribose co-eluted with xylose. In those instances an average $\delta^{13} \mathrm{C}$ value for co-eluting peaks was determined.

Except for Phaeocystis sp., all $\delta^{13} \mathrm{C}$ values of the monosaccharides were enriched in ${ }^{13} \mathrm{C}$ compared with $\delta^{13} \mathrm{C}_{\text {bulk }}$ (values of bulk cell material; Table 2, Fig. 4), i.e. 2 to $9 \%$ for glucose, 5 to $7 \%$ ofor xylose and 6 to $8 \%$ o for arabinose. In contrast, the monosaccharides $\delta^{13} \mathrm{C}$ were depleted up to $4 \%$ in ${ }^{13} \mathrm{C}$ relative to the $\delta^{13} \mathrm{C}_{\text {bulk }}$ value, for Phaeocystis sp. Compared with previous reports (e.g. Wong et al. 1975, Deines 1980) the magnitude of these differences is greater than has been reported on the basis of bulk determinations of monosaccharides. These differences are also far more variable than previously reported. This indicates a large heterogeneity in the relative isotopic compositions of monosaccharides in photoautotrophic organisms. The large enrichment (up to $8 \%$ ) in ${ }^{13} \mathrm{C}$ of the individual monosaccharides relative to $\delta^{13} \mathrm{C}_{\text {bulk }}$ in the case of the Sphagnum species (S. cuspidatum) is surprising, since the ${ }^{13} \mathrm{C}$ content of monosaccharides versus bulk material found by Macko et al. (1990) for a Sphagnum species were significantly different (depleted by up to $1 \%$ ). The reason for this could be that different Sphagnum species have different isotopic contents. Another difference between the 2 studies is the fact that Macko et al. used the alditol acetate method for isotopic analysis; this is prone to larger errors in $\delta^{13} \mathrm{C}$ determination (Van Dongen et al. 2001).

To explain the large ${ }^{13} \mathrm{C}$-enrichment of monosaccharides we have to take into account that other biochemicals, such as lipids, are generally depleted in ${ }^{13} \mathrm{C}$ compared with monosaccharides (see below). The reason why the $\delta^{13} \mathrm{C}_{\text {bulk }}$ of the Phaeocystis sp. was enriched compared with the $\delta^{13} \mathrm{C}$ values of the different monosaccharides could be the fact that this was a bloom sample. It is possible that isotopic fractionation within the cell during bloom conditions may be different than during non-bloom conditions. In addition, it is possible

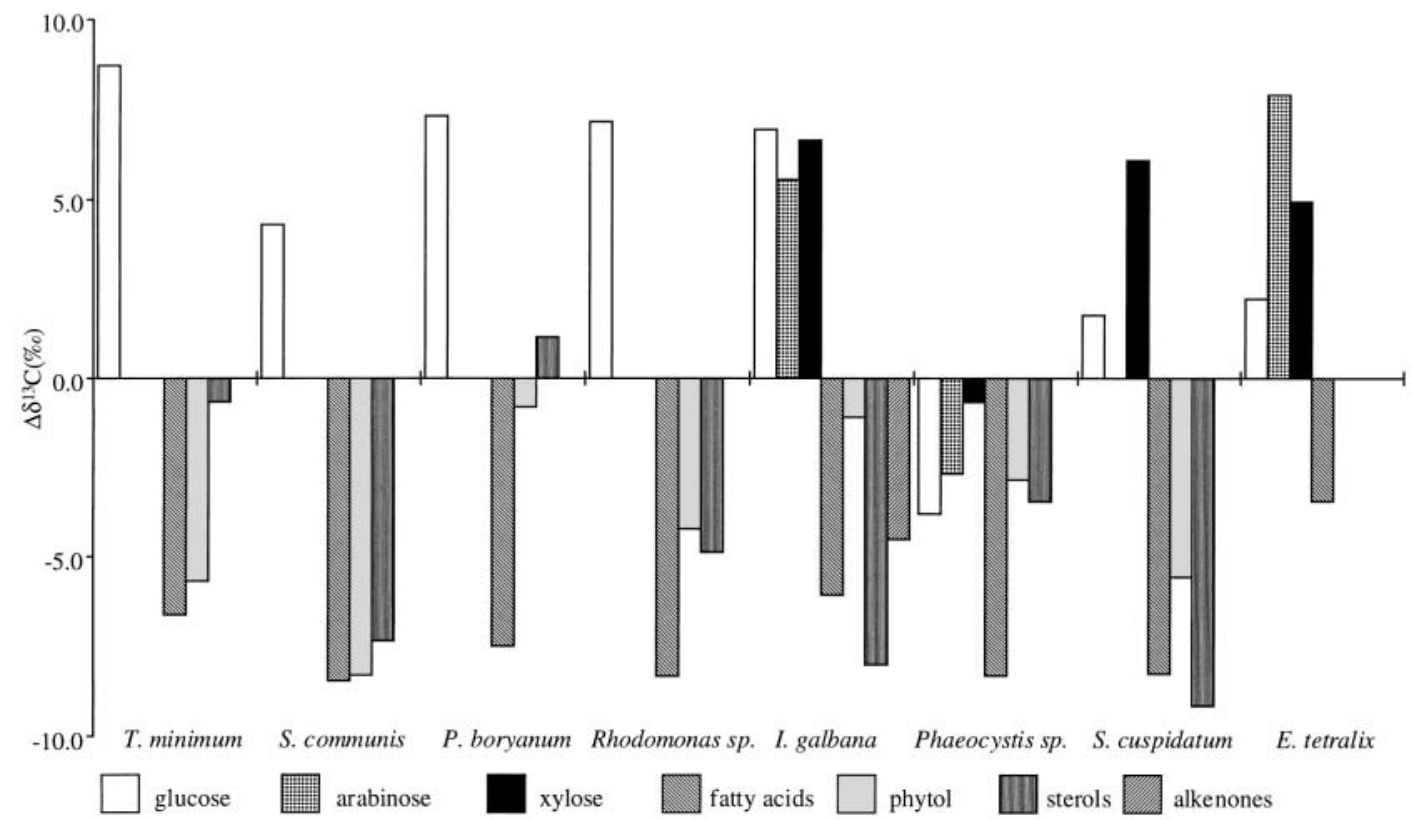

Fig. 4. $\delta^{13} \mathrm{C}$ values of monosaccharides and lipids relative to $\delta^{13} \mathrm{C}_{\mathrm{bulk}}$ in different aquatic and terrestrial organisms. The $\delta^{13} \mathrm{C}$ values of the fatty acids and sterols used are the average values of the $\mathrm{C}_{14}-\mathrm{C}_{18}$ fatty acids and $\mathrm{C}_{27}-\mathrm{C}_{29}$ sterols, respectively. Full specific names as in Table 1 


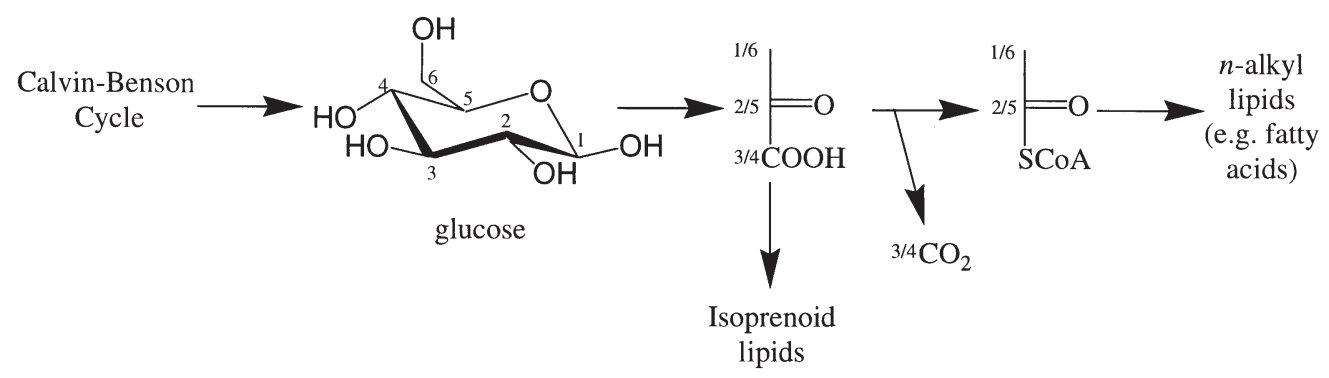

Fig. 5. Biosynthesis of fatty acids and isoprenoids starting from glucose. Carbon atoms are numbered according to their original position in the glucose carbon skeleton

fatty acids and $\mathrm{C}_{28}-\mathrm{C}_{29}$ sterols. Minor amounts of $\mathrm{C}_{21}$ $\mathrm{C}_{23} n$-alkanes, triterpenoids and wax esters were found, with a distribution similar to those reported for S. cuspidatum by Baas et al. (2000). Significant amounts of phytol were found in $S$. cuspidatum. Phytol is the main alkyl side chain of chlorophyll and no chlorophyll is present in roots, and hence it was not present in the roots of $E$. tetralix.

When possible, the $\delta^{13} \mathrm{C}$ of the lipids were determined, for comparison with the $\delta^{13} \mathrm{C}$ of the different monosaccharides (Table 2). As the unsaturated and saturated $\mathrm{C}_{18}$ fatty acids were often co-eluting, an average $\delta^{13} \mathrm{C}$ value of the total cluster of unsaturated and saturated $\mathrm{C}_{18}$ fatty acids was determined. For the same reasons, the average $\delta^{13} \mathrm{C}$ value of the $\mathrm{C}_{37}$ and $\mathrm{C}_{38}$ alkenones were determined in Isochrysis galbana. The fatty acids were considerably depleted in ${ }^{13} \mathrm{C}$ compared with glucose (Table 2, Fig. 4), i.e. the $\mathrm{C}_{14}-\mathrm{C}_{18}$ fatty acids were 12 to $16 \%$ depleted for freshwater and marine algal cultures, 3 to $6 \%$ for Phaeocystis sp., and 5 to $13 \%$ for terrestrial plants. Phytol and sterols were generally less depleted in ${ }^{13} \mathrm{C}$ compared with glucose (Table 2) than the fatty acids, i.e. phytol was 8 to $14 \%$ depleted for the freshwater and marine algal cultures and about $7 \%$ depleted in ${ }^{13} \mathrm{C}$ for Sphagnum cuspidatum. In contrast, the $\delta^{13} \mathrm{C}$ value of phytol from Phaeocystis sp. was similar to that of glucose. The sterols were 6 to $15 \%$ depleted compared with glucose in the freshwater and marine algal cultures and about $11 \%$ depleted in ${ }^{13} \mathrm{C}$ in $S$. cuspidatum. In contrast, the $\mathrm{C}_{27}$ sterol as well as the $\mathrm{C}_{28}$ sterol measured in Phaeocystis sp. were similar in ${ }^{13} \mathrm{C}$ compared with glucose. The alkenones in I. galbana were 11 to $12 \%$ o depleted in ${ }^{13} \mathrm{C}$ compared to glucose. The isotopic differences between the fatty acids, phytol, the sterols and the alkenones in the algal cultures are comparable to those reported previously by Schouten et al. (1998).

An enrichment in ${ }^{13} \mathrm{C}$ of monosaccharides compared to lipids has been generally assumed (Hayes 1993, 2001). However, the magnitude of the difference between monosaccharides and lipids determined here is far greater than has been anticipated. The reason for the depletion of lipids versus monosaccharides is assumed to be a consequence of kinetic isotope effects during enzymatic reactions. Glucose is formed in the Calvin-Benson cycle during photosynthesis. Subsequently, the glucose is cleaved to 2 pyruvate molecules, which are converted to acetyl coenzyme A through decarboxylation (Fig. 5). n-alkyl lipids are synthesized starting from acetyl coenzyme A and isoprenoid lipids are synthesized from pyruvate (Hayes 1993, 2001, Rohmer et al. 1993, Schwender et al. 1996, Lichtenthaler et al. 1997, Disch et al. 1998, and present Fig 5.). The decarboxylation from pyruvate to acetyl coenzyme $\mathrm{A}$ is associated with a kinetic isotopic fractionation effect (e.g. Monson \& Hayes 1980, 1982a,b, Melzer \& Schmidt 1987), leading to a depletion in ${ }^{13} \mathrm{C}$ in the carboxyl atom of acetyl coenzyme A. Thus, $n$-alkyl lipids are usually depleted in ${ }^{13} \mathrm{C}$ relative to the isoprenoid lipids constructed from pyruvate (Schouten et al. 1998). The different pathways may explain the differences in ${ }^{13} \mathrm{C}$ depletion between individual lipids and monosaccharides.

An alternative explanation for the ${ }^{13} \mathrm{C}$ depletion of lipids relative to monosaccharides may be the heterogeneous distribution of ${ }^{13} \mathrm{C}$ in glucose. During the decarboxylation of pyruvate to acetyl coenzyme A the original glucose carbon atoms 3 or 4 are removed. According to Rossmann et al. (1991), these carbon positions are relatively enriched in ${ }^{13} \mathrm{C}$ (about 2 to $6 \%$ ). This would mean that the acetyl coenzyme A unit formed is relatively depleted in ${ }^{13} \mathrm{C}$ compared with the pyruvate unit and consequently compared to glucose. Because straight-chain lipids are mainly constructed from acetyl coenzyme A, they are depleted in ${ }^{13} \mathrm{C}$ compared with glucose. However, as pointed out by Hayes (1993, 2001), this relative enrichment in ${ }^{13} \mathrm{C}$ of carbon atoms within glucose is too small to explain the observed large depletion in $\delta^{13} \mathrm{C}$ values of lipids. In addition, the difference between monosaccharides and lipids are even larger (up to $16 \%$ in $\delta^{13} \mathrm{C}$ ), and thus an even larger enrichment in ${ }^{13} \mathrm{C}$ within glucose is required. The observed differences between $\mathrm{C}_{5}$-monosaccharides and glucose indicate that the loss of a sin- 
gle carbon atom can lead to a significant difference in $\delta^{13} \mathrm{C}$ values (up to $6 \%$ ). This means that the potential difference in ${ }^{13} \mathrm{C}$ between the carbon atoms in glucose could be significantly larger than reported by Rossman et al. (1991). This makes the alternative explanation for the depletion of lipids, the heterogeneous distrubution of ${ }^{13} \mathrm{C}$ in glucose, more likely, although little is known about the pathways by which these $\mathrm{C}_{5}$-monosaccharides are formed.

\section{Influence of culture conditions on isotopic hetero- geneity of biochemicals}

The large range in differences in ${ }^{13} \mathrm{C}$ content between the monosaccharides, lipids and the bulk material for the different cultured algae could either be due to species-specific fractionation differences or to the culture conditions (e.g. Riebesell et al. 2000). In batch cultures, algae experience different growth conditions at the end of the log growth phase than at the beginning. This can result in changes in the culture medium, such as increasing $\mathrm{pH}$. In water there is a balance between the concentration of $\mathrm{CO}_{2}, \mathrm{HCO}_{3}{ }^{-}$and $\mathrm{CO}_{3}{ }^{2-}$. If the $\mathrm{pH}$ increases, this equilibrium is shifted to $\mathrm{CO}_{3}{ }^{2-}$, causing a relatively lower dissolved $\mathrm{CO}_{2}$ concentration (Hayes 1993, 2001). This means that less $\mathrm{CO}_{2}$ is available and relatively more enriched $\mathrm{CO}_{2}$ is incorporated, which will result in less ${ }^{13} \mathrm{C}$-depletion. Thus, these conditions probably result in less ${ }^{13} \mathrm{C}$-depletion at the end of the end of the log growth phase. In comparison, in the continuous culture there are constant limiting nutrient conditions, which will result in different, but consistent, isotopic fraction patterns. This will probably influence the differences in isotopic composition between the compounds in a single organism. Therefore, we cultured the same algae (Tetraedron minimum) under different conditions, i.e. under continuous culture and under batch culture conditions, and compared the two (Table 3). Glucose was approximately $7 \%$ enriched compared with $\delta^{13} \mathrm{C}_{\text {bulk }}$ and generally $10 \%$ enriched compared with the fatty acids in the continuous culture. Under batch culture conditions,

Table 3. Tetraedron minimum. $\delta^{13} \mathrm{C}_{\text {bulk }}$ and the $\delta^{13} \mathrm{C}$ values $(\%)$ of glucose and fatty acids (weighted mean average of $\mathrm{C}_{14^{-}}$ $\mathrm{C}_{18}$ fatty acids, with analytical error, which includes error in measurement as well as error through derivatization) under different culture conditions

\begin{tabular}{|lcc|}
\hline Component & Batch & Continuous \\
\hline Bulk material & $-47.9 \pm 0.1$ & $-34.7 \pm 0.1$ \\
Glucose & $-39.2 \pm 0.8$ & $-27.6 \pm 0.8$ \\
Fatty acids & $-53.6 \pm 0.3$ & $-37.6 \pm 0.3$ \\
\hline
\end{tabular}

glucose was approximately 9\% enriched compared with $\delta^{13} \mathrm{C}_{\text {bulk }}$ and generally $15 \%$ enriched enriched compared with the fatty acids.

The differences in isotopic content between the monosaccharides, lipids and the bulk material for the different cultures of Tetraedron minimum (batch versus continuous: Table 3) seem to support the assumption that culture conditions can influence the differences in ${ }^{13} \mathrm{C}$ content between monosaccharides, lipids and bulk material. Both types of cultures showed the same isotopic differences between fatty acids, monosaccharides and bulk. However, it seems that the different culture conditions influenced the isotopic composition of the fatty acids more than glucose compared with bulk-material values.

Differing growth conditions may also explain the difference between the results for cultured algae and those for the natural bloom sample.

\section{Conclusions}

From our results it is clear that large isotopic differences can exist in ${ }^{13} \mathrm{C}$ content between monosaccharides, lipids and bulk material in photoautotrophic organisms. These organisms comprise the base of the aquatic food-web chain and, depending on the (relative) assimilation of their different biochemicals components, they determine the isotopic composition of heterotrophic bacteria and zooplankton. Zooplankton can alter their bulk isotopic composition through selective assimilation of ingested compounds. Recent studies showed that components like carbohydrates are relatively easily digested and selectively assimilated (e.g. Cowie \& Hedges 1996). Thus, not the $\delta^{13} \mathrm{C}$ values of the algae but the $\delta^{13} \mathrm{C}$ values of the carbohydrates (and amino acids) produced by these algae will mainly determine the $\delta^{13} \mathrm{C}$ values of the zooplankton.

Suspended particulate organic carbon (POC) and DOM originate from various sources-primary production, resuspended sediment and terrestrial detritus discharged by rivers. The $\delta^{13} \mathrm{C}_{\mathrm{DOM}}$ and $\delta^{13} \mathrm{C}_{\mathrm{POC}}$ signal is often used as a biomarker indicating the origin of the organic matter (e.g. Salomons \& Mook 1981, Fry \& Sherr 1984, Laane et al. 1990, Mook \& Tan 1991). Organic matter produced by marine phytoplankton is assumed to have an average $\delta^{13} \mathrm{C}$ value of $-21 \%$, while terrestrial C-3 plant-derived organic matter has a content of $-27 \%$. DOM and POC consist, to a significant degree, of carbohydrates and, as shown in this study, monosaccharides are significantly enriched in ${ }^{13} \mathrm{C}$ compared with the isotopic composition of the total cell material. This would mean that if the amount of carbohydrates present in the DOM and POC differ significantly, the $\delta^{13} \mathrm{C}_{\mathrm{DOM}}$ and $\delta^{13} \mathrm{C}_{\mathrm{POC}}$ signals will also differ 
significantly. This will make it more difficult to distinguish between the different sources of the organic matter based solely on $\delta^{13} \mathrm{C}_{\mathrm{DOM}}$ and $\delta^{13} \mathrm{C}_{\mathrm{POC}}$ signals, and alternative methods need to be used, e.g. ${ }^{14} \mathrm{C}$ analysis (Megens et al. 1998).

Acknowledgements. We thank P. Blokker, W. C. M. Klein Breteler and M. Baas for supplying samples, and W. C. M. Klein Breteler and 3 anonymous referees for their useful comments on the manuscript. H. T. Kloosterhuis is acknowledged for performing bulk carbon isotope measurements. M. Kienhuis, J. P. Werne, E. Schefuss and R. D. Pancost are thanked for analytical assistance, and M. van der Meer for helpful discussions. This research was supported by the NetherlandsBremen Oceanography Program (NEBROC). This is NIOZ contribution 3655

\section{LITERATURE CITED}

Aspinall JJ (1983) The polysaccharides, Vol 2. Academic Press, New York

Baas M, Pancost RD, van Geel B, Sinninghe Damsté JS (2000) A comparative study of lipids in Sphagnum species. Org Geochem 31:535-541

Benner B, Pakulski JD, McCarthy M, Hedges J, Hatcher PG (1992) Bulk chemical characteristics of dissolved organic matter in the ocean. Science 255:1561-1564

Blokker P, Schouten S, van den Ende H, de Leeuw JW, Sinninghe Damsté JS (1998a) Cell wall-specific $\omega$-hydroxy fatty acids in some freshwater green microalgae. Phytochemistry 49:691-695

Blokker $\mathrm{P}$, Schouten $\mathrm{S}$, van den Ende $\mathrm{H}$, de Leeuw JW, Hatcher PG, Sinninghe Damsté JS (1998b) Chemical structure of algaenans from the fresh water algae Tetraedron minimum, Scenedesmus communis and Pediastrum boryanum. Org Geochem 29:1453-1468

Borch NH, Kirchman DL (1997) Concentration and composition of dissolved combined neutral sugars (polysaccharides) in seawater determined by HPLC-PAD. Mar Chem 57:85-95

Burdige DJ, Skoog A, Gardner K (2000) Dissolved and particulate carbohydrates in contrasting marine sediments. Geochim Cosmochim Acta 64:1029-1041

Cowie GL, Hedges JI (1996) Digestion and alteration of the biochemical constituents of a diatom (Thalassiosira weissflogii) ingested by an herbivorous zooplankton (Calanus pacificus). Limnol Oceanogr 41:581-594

Cowie GL, Hedges JI, Calvert SE (1992) Sources and relative reactivities of amino acids, neutral sugars, and lignin in an intermittently anoxic marine environment. Geochim Cosmochim Acta 56:1963-1978

Deines P (1980) The isotopic composition of reduced organic carbon. In: Fritz P, Fontes JCh (eds) Handbook of environmental isotope geochemistry. Elsevier Science, Amsterdam, p 329-406

Disch A, Schwender J, Muller C, Lichtenthaler HK, Rohmer M (1998) Distribution of the mevalonate and glyceraldehyde phosphate/pyruvate pathways for isoprenoid biosynthesis in unicellular algae and the cyanobacterium Synechocystes PCC 6714. Biochem J 333:381-388

Fry B, Sherr EB (1984) $\delta^{13} \mathrm{C}$ measurements as indicators of carbon flow in marine and freshwater ecosystems. Contrib Mar Sci 27:13-47
Fry B, Brand W, Mensch FJ, Tholke K, Garritt R (1992) Automatic analysis system for coupled $\delta^{13} \mathrm{C}$ and $\delta^{15} \mathrm{~N}$ measurements. Anal Chem 64:288-291

Gocke K (1975) Untersuchungen über die Aufname von gelöster Glukose unter natürlichen Verhältnissen durch grössenfraktioniertes Nano- und Ultrananoplankton. Kiel Meeresforsch 31:87-94

Grice K, Klein Breteler WCM, Schouten S, Grossi V, de Leeuw JW, Sinninghe Damsté JS (1998) Effects of zooplankton herbivory on biomarker proxy records. Paleoceanography 13:686-693

Guillard RRL (1975) Culture of phytoplankton for feeding marine invertebrates. In: Smith WL, Chanley MH (eds) Culture of marine invertebrate animals. Plenum Press, New York, p 29-60

Hayes JM (1993) Factors controlling ${ }^{13} \mathrm{C}$ content of sedimentary organic compounds: principles and evidence. Mar Geol 113:111-125

Hayes JM (2001) Fractionation of carbon and hydrogen isotopes in biosynthetic processes. In: Valley JW, Cole DR (eds) Stable isotope geochemistry. Reviews in mineralogy and geochemistry, Vol 43. Mineralogical Society of America, Washington, DC

Hedges JI (1992) Global biogeochemical cycles: progress and problems. Mar Chem 39:67-93

Ivlev AA, Lapin AV, Brizanova LYA (1987) Distribution of carbon isotopes $\left({ }^{13} \mathrm{C} /{ }^{12} \mathrm{C}\right)$ in the glucose of maize starch. Fiziol Rast (Mosc) 34:493-498

Klok J, Cox HC, de Leeuw JW, Schenck PA (1982) Analysis of synthetic mixtures of partially methylated alditols acetates by capillary gas chromatography, gas chromatographyelectron impact mass spectrometry and gas chromatography-chemical ionization mass spectrometry. J Chromatogr 253:55-64

Klok J, Cox HC, Baas M, Schuyl PJW, de Leeuw JW, Schenck PA (1984) Carbohydrates in recent marine sediments. I. Origin and significance of deoxy- and O-methyl-monosaccharides. Org Geochem 7:73-84

Laane R, Turkstra E, Mook W (1990) Stable carbon isotopic composition of palagic and benthic organic matter in the North Sea and adjacent estuaries. In: Ittekot V, Kempe S, Michaelis W, Spitzy A (eds) Facets of modern biogeochemistry. Springer-Verlag, Berlin, p 214-224

Lichtenthaler HK, Schwender J, Disch A, Rohmer M (1997) Biosynthesis of isoprenoids in higher plants chloroplasts proceeds via a mevalonate independant pathway. FEBS Lett 400:271-274

Macko SA, Helleur R, Hartley G, Jackman P (1990) Diagenesis of organic matter-a study using stable isotopes of individual carbohydrates. Org Geochem 16:1129-1137

Macko SA, Ryan M, Engel MH (1998) Stable isotopic analysis of individual carbohydrates by gas chromatographic/combustion/isotope ratio mass spectrometry. Chem Geol 152: 205-210

Marlowe IT, Brassell SC, Eglinton G, Green JC (1984) Longchain unsaturated ketones and esters in living algae and marine sediments. Org Geochem 6:135-141

Megens L, van der Plicht J, de Leeuw JW (1998) Molecular, radioactive and stable carbon isotope charaterization of estuarine particulate organic matter. Radiocarbon 40:985-990

Melzer E, Schmidt HL (1987) Carbon isotope effects on the pyruvate dehydrogenase reaction and their importance for relative carbon-13 depletion in lipids. J Biol Chem 262: $8159-8164$

McCarthy M, Hedges J, Benner R (1996) Major biochemical composition of dissolved high molecular weight organic matter in seawater. Mar Chem 55:281-297 
Michener RH, Schell DM (1994) Stable isotope ratios as tracers in marine aquatic food webs. In: Lajtha $\mathrm{K}$, Michener RH (eds) Stable isotopes in ecology and environmental science. Blackwell Science, Oxford, p 138-157

Monson KD, Hayes JM (1980) Biosynthesis control of the natural abundance of carbon 13 at specific positions within fatty acids in Escherichia coli. J Biol Chem 255: $11435-11441$

Monson KD, Hayes JM (1982a) Biosynthetic control of the natural abundance of carbon 13 at specific positions within fatty acids in Saccharomyces cerevisiae. J Biol Chem 257:5568-5575

Monson KD, Hayes JM (1982b) Carbon isotopic fractionation in the biosynthesis of bacterial fatty acids: ozonolysis of unsaturated fatty acids as a means of determining the intramolecular distribution of carbon isotopes. Geochim Cosmochim Acta 46:139-149

Mook WG, Tan FC (1991) Stable carbon isotopes in rivers and Estuaries. SCOPE 42:245-264

Mopper K, Dawson R, Liebezeit G, Ittekkot V (1980) The monosaccharide spectra of natural waters. Mar Chem 10: 55-66

Pakulski JD, Benner R (1994) Abundance and distribution of carbohydrates in the ocean. Limnol Oceanogr 39:930-940

Parsons TR, Takahashi M, Hardgrave B (1984) Biological oceanographic processes. Pergamon Press, Oxford

Reinhold VN, Wirtz-Peitz F, Biemann K (1974) Synthesis, gasliquid chromatography, and mass spectrometry of per$o$-trimethylsilyl carbohydrate boronates. Carbohydr Res 37:203-221

Riebesell U, Revill AT, Holdsworth DG, Volkman JK (2000) The effects of varying $\mathrm{CO}_{2}$ concentration on lipid composition and carbon isotope fractionation in Emiliania huxleyi. Geochim Cosmochim Acta 64:4179-4192

Rohmer M, Knani M, Simonin P, Sutter B, Sahm H (1993) Isoprenoid biosynthesis in bacteria: a novel pathway for the early steps leading to isopentenyl diphosphate. Biochem J 295:517-524

Rossmann A, Butzenlechner M, Schmidt HL (1991) Evidence for a nonstatistical carbon isotope distribution in natural glucose. Plant Physiol 96:609-614

Salomons W, Mook WG (1981) Field observations of the istopic composition of particulate organic carbon in the soutern North Sea and adjacent estuaries. Mar Geol 41: $11-20$

Schouten S, Klein Breteler WCM, Blokker P, Schogt N, Rijpstra WIC, Grice K, Baas M, Sinninghe Damsté JS (1998)

Editorial responsibility: Barry \& Evelyn Sherr (Contributing Editors), Corvallis, Oregon, USA
Biosynthetic effects on the stable carbon isotopic composition of algal lipids: implications for deciphering the carbon isotopic biomarker record. Geochim Cosmochim Acta 62: 1397-1406

Schwender J, Seemann M, Lichtenthaler HK, Rohmer M (1996) Biosynthesis of isoprenoids (carotenoids, sterols, prenyl sidechains of chlorophylls and plastoquinone) via a novel pyruvate/glyceraldehyde 3-phosphate non-mevalonate pathway in the green algae Scenedesmus obliquus. Biochem J 316:73-80

Sjöström E (1981) Wood chemistry, fundamentals and applications. Academic Press, New York

Skoog A, Benner R (1997) Aldoses in various size fractions of marine organic: implications for carbon cycling. Limnol Oceanogr 42:1803-1813

Tissot E, Welte DH (1978) Petroleum formation and occurrence. Springer-Verlag, Berlin

Van der Zanden MJ, Casselman JM, Rasmussen JB (2000) Stable isotope evidence for the food web consequences of species invasions in lakes. Nature 401:464-466

Van Dongen BE, Schouten S, Sinninghe Damsté JS (2001) Gas chromatography/combustion/isotope-ratio-monitoring mass spectrometric analysis of methylboronic derivatives of monosaccharides: a new method for determining natural ${ }^{13} \mathrm{C}$ abundances of carbohydrates. Rapp Comm Mass Spectrometry 15:496-500

Volkman JK, Eglinton G, Corner EDS, Sargent JR (1980) Long-chain alkenes and alkenones in the marine coccolithophorid Emiliania huxleyi. Phytochemistry 19: 2619-2622

Williams PJ leB, Yentsch CS (1976) An examination of the photosynthetic production, excretion of photosynthic products, and heterotrophic utilization of dissolved organic compounds with reference to results from a coastal subtropical sea. Mar Biol 35:31-40

Wong W, Sackett WM, Benedict CR (1975) Isotope fractionation in photosynthetic bacteria during carbon dioxide assimilation. Plant Physiol 55:475-479

Wood BJB (1988) Lipids of algae and protozoa. In: Ratledge C, Wilinson SG (eds) Microbial lipids. Academic Press, New York, p 807-842

Wright RT, Hobbie JE (1966) Use of glucose and acetate by bacteria and algae in aquatic ecosystems. Ecology 47: 447-468

Yoshii K, Melnik NG, Timoshkin OA, Bondarenko NA, Anoshko PN (1999) Stable isotope analyses of the pelagic food web in Lake Baikal. Limnol Oceanogr 44:502-51

Submitted: September 17, 2000; Accepted: January 2, 2001

Proofs received from author(s): April 5, 2002 